\title{
Microstructure Evolution at Severely-deformed Ferrite/Martensite Interfaces in a Layer-integrated Steel
}

\author{
Taisuke HAYASHI and Eiji ABE \\ Department of Materials Science \& Engineering, The University of Tokyo, Tokyo 113-8656 Japan. \\ E-mail: abe@material.t.u-tokyo.ac.jp
}

(Received on July 13, 2009; accepted on November 13, 2009)

\begin{abstract}
The microstructure evolution at interfaces of a layer-integrated steel sheet constructed by ferritic (SPCC) and martensitic stainless (SUS420J2) steel layers, which were bonded through a cold-rolling and subsequently annealed at $1000^{\circ} \mathrm{C}$, has been investigated using scanning transmission electron microscopy combined with energy dispersive X-ray spectroscopy. We find that microstructures around the SPCC/SUS420J2 interfaces are significantly reconstructed during a short-time annealing at $1000^{\circ} \mathrm{C}$ followed by quenching into water, and the resultant ferrite/martensite interface is found to be extended into the SPCC side from the original cold-rolled interface. Occurrence of such interface migration can be reasonably explained as due to a martensitic transformation across the composition-gradient interface that is caused by element diffusions during annealing at $1000^{\circ} \mathrm{C}$. These microstructural characteristics are discussed by comparing with our recent observations of austenite (SUS304)/martensite (SCM415) interface microstructures (Hayashi et al., ISIJ Int., 49 (2009), 1406), which are formed via the same rolling/annealing procedures, aiming to provide a common aspect on how the strong bonding between the hetero-interfaces can be achieved in the layer-integrated steels.
\end{abstract}

KEY WORDS: steels; interface structure; scanning transmission electron microscopy; phase transformation; severe plastic deformation.

\section{Introduction}

Laminated multi-layered steels (MLS) constructed by brittle and ductile steels are of interest because of their unique mechanical properties. ${ }^{1-6)}$ One of the remarkable phenomena with MLS is that even the brittle martensite layers reveal significant elongation when they are sandwiched by ductile steels (e.g., austenitic stainless steel (SUS304)/martensitic steel MLS ${ }^{7}$ ), encouraging a further potential of MLS with a successful combination of brittle/ ductile steels. For fabrication of MLS, an important key process is to realize the strong bonding between the dissimilar steels.

In the recent studies, ${ }^{7-9)}$ laminate-composites of MLS were produced through a cold rolling and a subsequent short-time annealing process, in order to avoid decarburizations and resultant softening of the hard high-carbon steel layers. In the studies, bonding strength as well as tensile behaviors of MLS was investigated according to a unique "peel test"9,10) for the strength evaluation at the bonding interface. It was found that both the tensile and bonding properties are remarkably improved after applying a short-time annealing on the cold-rolled MLS specimen. To clarify how the strong bonding between the dissimilar steels can be achieved, we recently investigated microstructure evolutions around the interfaces in a martensite (SCM415)/ austenite (SUS304) MLS during the short-time annealing at $1000^{\circ} \mathrm{C}$ followed by quenching into water. ${ }^{11)}$ We concluded that the interface bonding is primary accomplished during holding at $1000^{\circ} \mathrm{C}$, where the SCM415/SUS304 interfaces are fully covered by the fresh austenite grains being across the original interface. Besides, an important subsequent step is a martensitic transformation propagated from the $\mathrm{SCM} 415$ layer during quenching from $1000^{\circ} \mathrm{C}$, forming the lath martensite that protrudes across the original interface but terminates within the austenite grain interiors. These microstructural features of the SCM415/SUS304 interface fairly well explained how the strong bonding is achieved through the cold rolling/annealing process. ${ }^{11)}$

In the present work, we pay attention to a laminated MLS constructed by a high-strength martensitic steel (SUS420J2) and a ductile ferritic steel (SPCC), for which microstructures of both the SUS420J2 and SPCC will be reconstructed via the martensitic and ferritic transformations during quenching, respectively. We investigate the microstructure evolution of the cold-rolled SPCC/ SUS420J2 interfaces during annealing at $1000^{\circ} \mathrm{C}$ followed by quenching into water, by using transmission electron microscopy (TEM) and scanning transmission electron microscopy (STEM) combined with energy dispersive spectroscopy (EDS). On the basis of the observed microstructures, we will discuss the bonding mechanism of the SPCC/SUS420J2 hetero-interfaces, by comparing with the characteristics of the previous SCM415/SUS304 interface. $^{11)}$ 


\section{Experimental Procedure}

For microstructural studies of the SPCC/SUS420J2 interface, a three-layered sheet was designed using commercialgrade roll steel SPCC and martensitic stainless steel SUS420J2; the SUS420J2 layer is sandwiched by the two SPCC layers. Compositions of these steels are summarized in Table 1. The three-layered sheet was submitted to a cold rolling process with reduction of $\sim 60 \%$ in thickness, and consequently the SPCC and SUS420J2 layers become $0.16 \mathrm{~mm}$ and $0.33 \mathrm{~mm}$ in final thickness, respectively (see Fig. 1 in Ref. 11 for details of specimen dimensions). Figure 1 shows the as-rolled SPCC/SUS420J2 microstructure by scanning electron microscopy (SEM), revealing that some thick oxide blocks $(0.5-1 \mu \mathrm{m}$ in thickness) are sparsely distributed along the as-rolled interface (see white arrows in Fig. 1) at which obvious voids are not observed at this magnification. The oxide blocks are presumably inherited from the original surface oxide layers (the sheet surfaces have been scratch-brushed before the cold-rolling ${ }^{9}$ ), and, in fact, similar block oxides were also observed for the previous as-rolled SCM415/SUS304 interface treated by

Table 1. Compositions of the cold-roll steel SPCC and martensitic stainless steel SUS420J2 in mass\%.

\begin{tabular}{lllllll}
\hline & $\mathrm{C}$ & $\mathrm{Si}$ & $\mathrm{Mn}$ & $\mathrm{P}$ & $\mathrm{S}$ & $\mathrm{Cr}$ \\
\hline SPCC & 0.03 & 0.01 & 0.16 & 0.009 & 0.010 & - \\
SUS420J2 & 0.32 & 0.79 & 0.60 & 0.025 & 0.002 & 13.52 \\
\hline
\end{tabular}

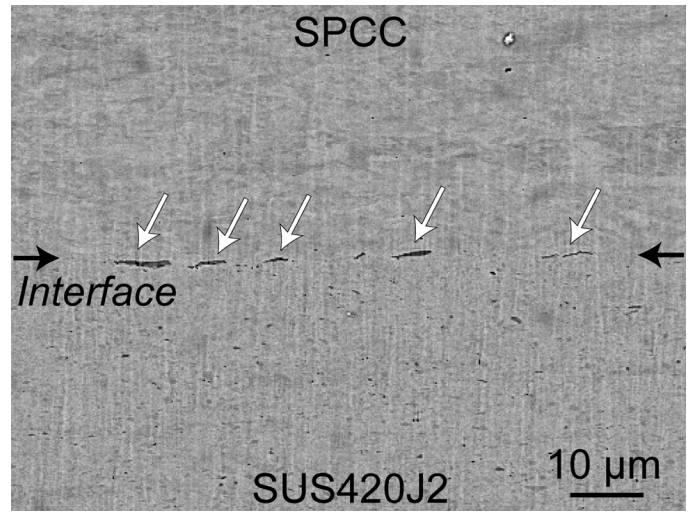

Fig. 1. SEM image for an interface of an as-rolled specimen. Oxide blocks are seen as the dark regions at the interface. the same manner. ${ }^{11,12)}$ In the present work, we investigate microstructure evolutions at the apparently well-bonded interface region in Fig. 1 (namely, we do not deal with any microstructural change of the block oxides during the subsequent annealing).

The rolled samples were annealed at $1000^{\circ} \mathrm{C}$ for $0-10$ min followed by quenching into water (" $0 \mathrm{~min}$ " annealing means that the specimen was immediately quenched when it reached the annealing temperature $1000^{\circ} \mathrm{C}$ ). Note that water quenching is essential to obtain strong martensite structure for the SUS420J2 layer. For TEM observation, small pieces of the laminated sheets were cut along the rolling direction (RD), and then they were polished by $\mathrm{SiC}$ abrasive paper and diamond paste, and finally they were thinned by a Gatan PIPS ion mill. TEM and STEM-EDS observations were performed by a JEOL $2010 \mathrm{~F}$ field emission gun microscope equipped with an EDS detector at an acceleration voltage of $200 \mathrm{kV}$. Composition mapping analysis was constructed by using $\mathrm{C}-\mathrm{K}$, $\mathrm{O}-\mathrm{K}, \mathrm{Si}-\mathrm{K}, \mathrm{Mn}-\mathrm{K}, \mathrm{Fe}-\mathrm{K}$, and $\mathrm{Cr}-\mathrm{K}$ lines.

\section{Result and Discussion}

\subsection{Microstructure Change around the Interfaces}

Figures 2(a)-2(d) show bright-field (BF) images of an as-rolled (Figs. 2(a) and 2(b)) and annealed/quenched specimens (Figs. 2(c) and 2(d)). In the as-rolled specimen, both the SPCC and SUS420J2 layers show severely deformed microstructures of ferrite and martensite, respectively, exhibiting elongated grain morphologies along the RD. It is noted that, at the as-rolled state, the SPCC/SUS420J2 interface is weakly bonded and hence easily delaminated during preparing a thin TEM specimen as shown in Figs. 2(a) and 2(b), even though it appeared to be almost well-bonded as shown in Fig. 1. After the annealing/quenching procedures, the microstructures of both the SPCC/SUS420J2 layers are remarkably reconstructed as shown in Figs. 2(c) and 2(d). Around the reconstructed SPCC/SUS420J2 interface, there are two notable features being in common with the previous SCM415/SUS304 reconstructed interface; i) fine precipitates along the original interfaces, and ii) reconstructed ferrite/martensite interface has been shifted from the original as-rolled interface. To clarify how these microstructural features have been generated, we should first remind the phase transformations during the annealing/quenching, which are summarized in Fig. 3. For the present SPCC/
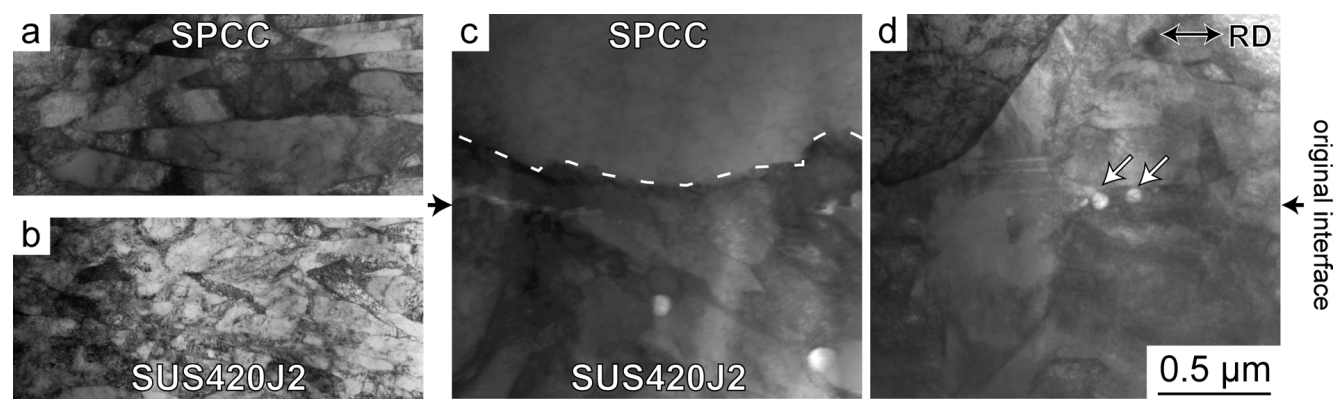

Fig. 2. Bright-field TEM images for (a) the SPCC layer and (b) SUS420J2 layer obtained around the as-rolled SPCC/SUS420J2 interface, which have been delaminated during preparing thin TEM foils. Bright-field STEM images of the SPCC/SUS420J2 interfaces subsequently annealed for (c) $0 \mathrm{~min}$ and (d) 2 min, respectively. The rolling direction and original interfaces are parallel to the horizontal line. 


\begin{tabular}{|c|c|c|c|c|c|}
\hline \multicolumn{2}{|c|}{ as-rollec } & \multicolumn{2}{|c|}{ at $1000^{\circ} \mathrm{C}$} & \multicolumn{2}{|c|}{$\begin{array}{l}\text { water- } \\
\text { quenched }\end{array}$} \\
\hline SPCC & $\alpha$ & $\begin{array}{c}\text { reverse } \\
\text { trans. }\end{array}$ & $\gamma$ & $\begin{array}{l}\text { ferritic } \\
\text { trans. }\end{array}$ & $\alpha$ \\
\hline SUS420J2 & $\boldsymbol{\alpha}$, & $\begin{array}{c}\text { reverse } \\
\text { trans. }\end{array}$ & $\gamma$ & $\begin{array}{c}\text { martensitic } \\
\text { trans. }\end{array}$ & ic \\
\hline
\end{tabular}

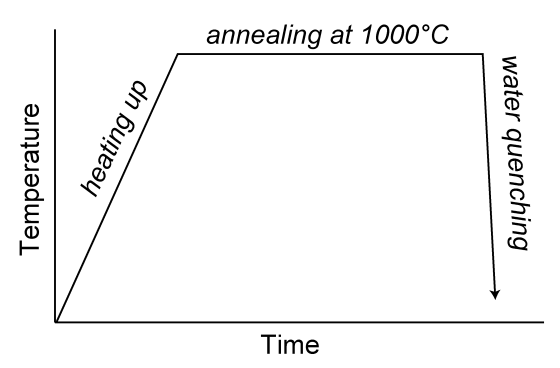

Fig. 3. Schematic diagram for the phase transformations of the SPCC and SUS420J2 layers during annealing and following water quenching.

SUS420J2 MLS, both the layers were mostly transformed into austenite at $1000^{\circ} \mathrm{C}$, and then transformed again into ferrite and martensite during quenching for the SPCC and SUS420J2, respectively. Generally, it is known that the SUS420J2 may not be fully transformed into austenite by annealing at $1000^{\circ} \mathrm{C}$ for a few minutes; though, most of the present SPCC/SUS420J2 interface microstructures were found to be fully reconstructed via austenization and the following transformations, as will be described in the followings. Perhaps this is due to that the reconstruction events have been proceeded under the conditions deviated from equilibrium, since there must exist a considerable amount of strains stored around the initial severely-deformed interface.

During holding at $1000^{\circ} \mathrm{C}$, the fresh austenite grains grow and stride over the original interfaces, being similar to the case for the SCM415/SUS304 interfaces. ${ }^{11)}$ As discussed in the previous paper, this is a primary stage to achieve strong bonding between the dissimilar steels by unifying the original cold-bonded interface. Here, concerning the characteristic feature i) mentioned above, the original as-rolled interface can be effectively traced by the small precipitates appeared within the martensite grain interiors, as indicated by arrows in Fig. 2(d). These fine particles are mostly identified as a crystalline silicon oxide by electron diffraction and EDS analyses (details will be described in the next section). According to the Ellingham diagram, among the elements in the present steels, silicon is the first to precipitate as the oxides by capturing the solute oxygen existed at the free surfaces of SPCC/SUS420J2 sheets before rolling. Therefore, it is reasonable to assume that these silicon-oxide particles have been precipitated at the asrolled original interfaces in the very early stage of annealing, perhaps being prior to the nucleation-growth of the fresh austenite grains. Then, these particles will be incorporated within the following martensite grain interiors during quenching, forming the resultant microstructure represented in Figs. 2(c) and 2(d). As mentioned in the second feature ii), having in mind that the silicon-oxide particles trace the original interface, it is evident that the reconstructed ferrite/martensite interfaces are penetrated into the
SPCC side (see the broken line in Fig. 2(c)) in the range $100-400 \mathrm{~nm}$ away from the original interface. Details of the ferrite/martensite interface migrations in terms of the martensitic transformation will be discussed later.

\subsection{Chemical Analyses around the Interfaces}

Figure 4 shows a representative example showing elemental distributions around the SPCC/SUS420J2 interface in the 0 -min annealed specimen. First to note is that siliconoxide fine particles are clearly identified (see arrows in Fig. 4(b)), being arrayed along the original interface. In addition, there also appear relatively large Cr-oxide particles at the original interface (Figs. 4(c) and 4(f)); the origin of these could be due to either the original surface oxide layer crashed into small pieces during the rolling or precipitation during the annealing (for the SUS420J2, Cr is the second likely element to precipitate according to the Ellingham diagram). In any cases, these oxide particles effectively trace the original interfaces.

There are several other types of Cr-rich particles identified within the SUS420J2 layer: a sigma phase particle in the left side, and a few carbide particles in the right side in Fig. 4(f). These particles are commonly observed for the SUS420J2 layer, and thus they were not precipitated during the annealing but just pre-existing precipitates in the original SUS420J2 sheets. From these considerations, except the fine oxides we conclude that there is no extensive precipitation around the present SPCC/SUS420J2 interfaces during the short-time annealing. This is in sharp contrast to the case of the previous SCM415/SUS304 interfaces, for which the short-time annealing caused a dense precipitation of $\mathrm{Cr}$ carbides at the SUS304 side. ${ }^{11)}$ Occurrence of such carbides was attributed to a fast carbon flow that forms a transient carbon concentration peak within the SUS304 layer during the early stage of annealing, accelerating the carbide formation at the Cr-rich region given with a sufficient amount of carbon supply (see Fig. 8 in Ref. 11)). For the present SPCC/SUS420J2 case, both the carbon and $\mathrm{Cr}$ are already rich in the SUS420J2 layer, and a certain amount of the carbon contents is already used for the Cr-carbide precipitations (Figs. 4(d) and 4(f)). With this situation, it is noteworthy that a mean difference of carbon chemical potential (in solution) between the SPCC/SUS420J2 is rather compensated, in spite of the apparent large difference of carbon compositions between them (Table 1). Less difference in the mean potentials may not cause extensive carbon-rich region around the interface of dissimilar steels, as reported by Million et al. for weld joints between a $18 \mathrm{Cr}-10 \mathrm{Ni}$ type stainless and chromium steels. ${ }^{13)}$ All in all, the carbide formation was not promoted around the present SPCC/ SUS420J2 interface during the short-time annealing.

Evolutions of element distributions across the SPCC/ SUS420J2 interface are summarized by the averaged line profiles in Fig. 5. The concentration profiles show smooth changes in the composition gradients; it is clearly seen that the $\mathrm{Cr}$ composition profile becomes broader with increasing annealing time, except for the local maximum peaks that correspond to the oxide particles and a trace of grain boundary diffusion (described later in Fig. 6). This suggests that a $\mathrm{Cr}$ transport has been basically achieved via a bulk interdiffusion within the prior austenite grains during an- 


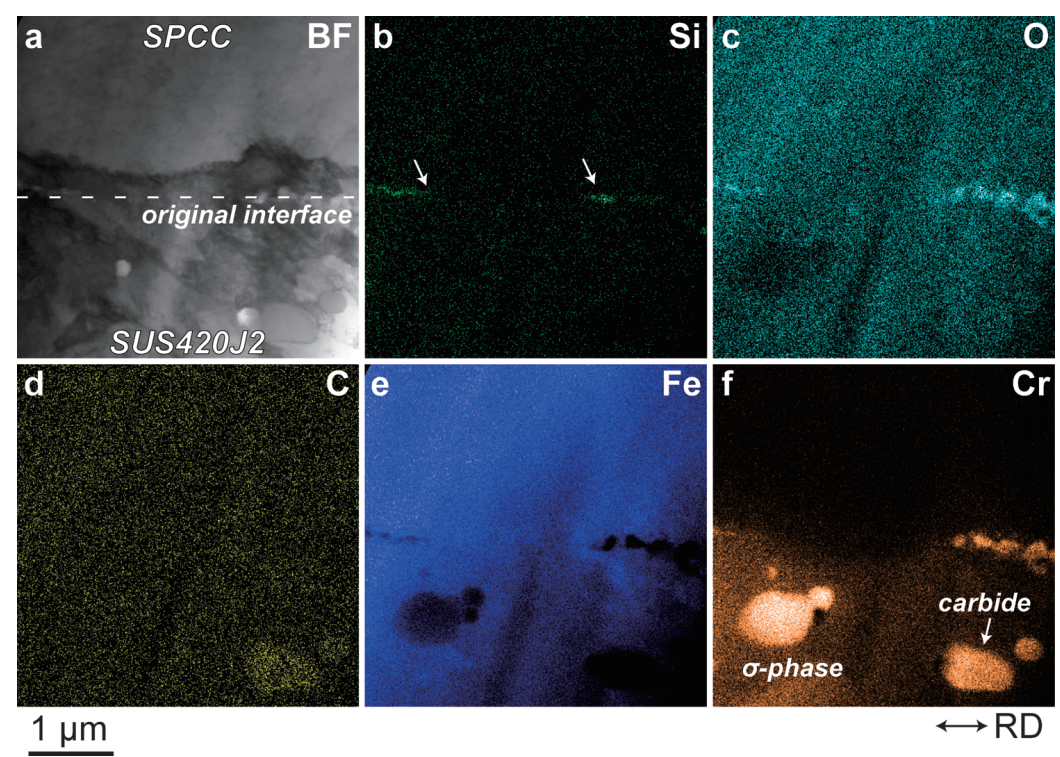

Fig. 4. Reconstructed interface microstructure with elemental distributions of the 0-min annealed specimen; (a) brightfield STEM image, and (b)-(f) elemental distributions of Si, O, C, Fe, and Cr, respectively.

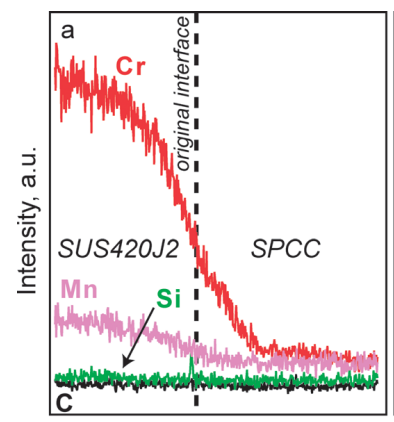

Distance

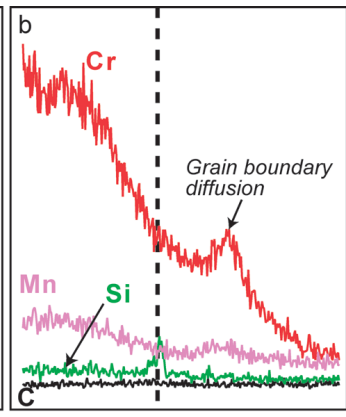

Distance

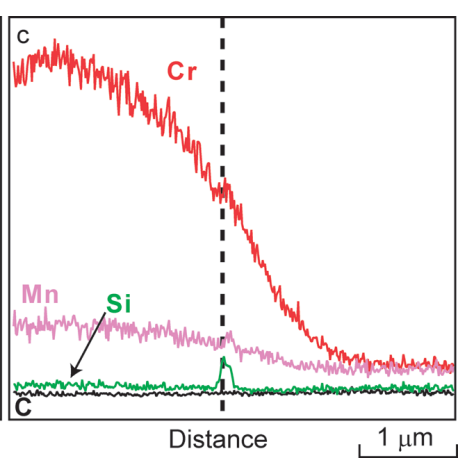

$1 \mu \mathrm{m}$

Fig. 5. (a)-(c) Averaged concentration profiles of C, Si, Mn, and Cr across the SPCC/SUS420J2 interfaces taken from the specimens annealed for 0,2 , and $10 \mathrm{~min}$, respectively. These profiles are obtained by integrating the spectra over the $\sim 0.5 \mu \mathrm{m}$ area along the interface.
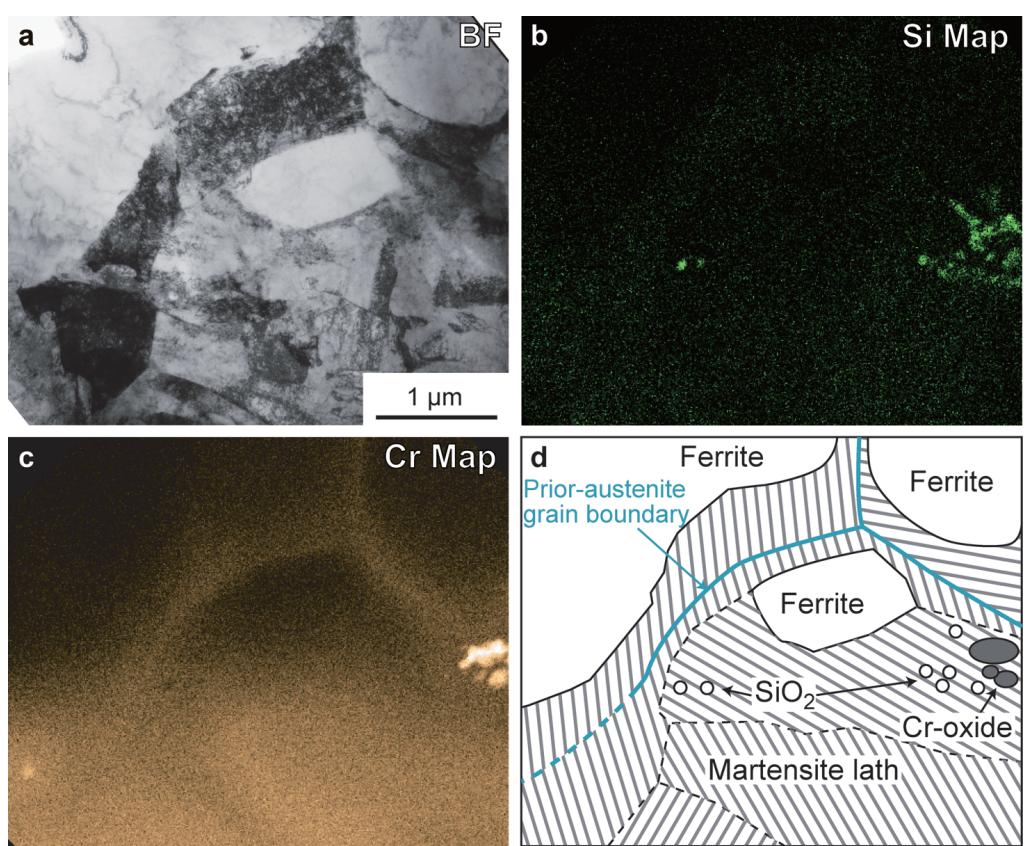

Fig. 6. SPCC/SUS420J2 interface microstructure of the 2-min annealed specimen; (a) bright-field TEM image showing the region where extensive grain boundary diffusion occurred, (b) Si and (c) Cr distributions corresponding to the area of (a), and (d) schematic illustration of the distributions of ferrite and martensite crystals. 

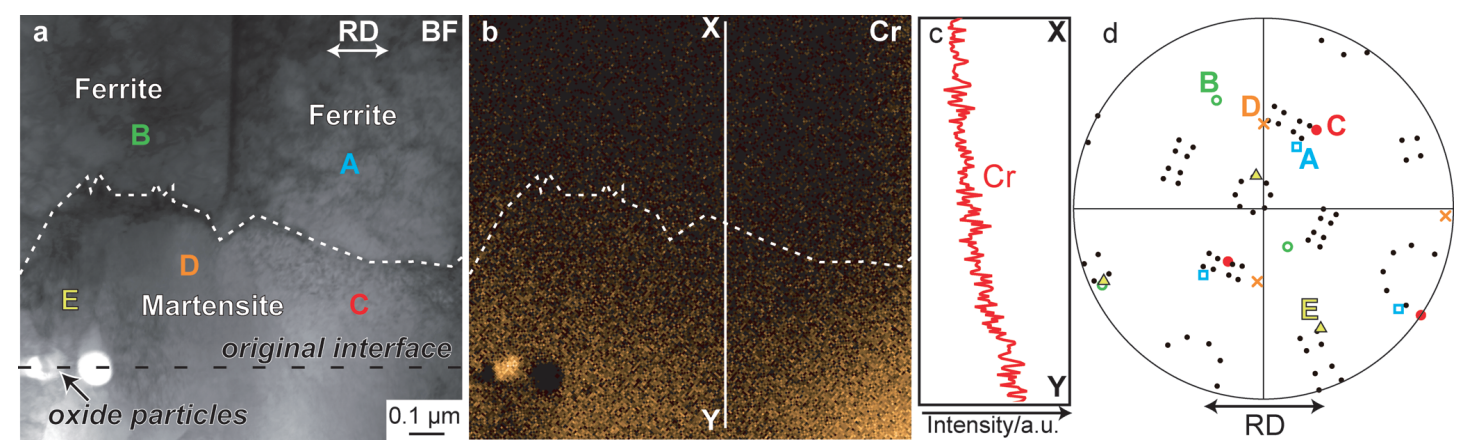

Fig. 7. (a) Bright-field STEM image of the ferrite/martensite interface in the 2-min annealed specimen, (b) Cr distribution map, (c) averaged concentration profile of $\mathrm{Cr}$ obtained from the region (b), and (d) $\langle 100\rangle$ pole figure for the grains denoted by $\mathbf{A}-\mathbf{E}$ with a possible arrangement for 24 variants derived from the Kurdjumov-Sachs orientation relationship. Note that the ferrite grains and martensite laths are reasonably interpreted as being generated from the single prior austenite grain.

nealing at $1000^{\circ} \mathrm{C}$. As will be discussed systematically in the next section, the $\mathrm{Cr}$ composition-gradient plays a critical role in determining whether ferritic or martensitic transformation becomes dominant at given local area around the interface, causing an obvious migration of the ferrite/ martensite interface from the original SPCC/SUS420J2 asrolled interface (Fig. 2(c)).

\subsection{Morphology/Crystallography of a Ferrite/Marten- site Interface}

As shown in Fig. 2(c), the reconstructed ferrite/martensite interface reveals continuous morphologies in a relatively low magnification image. However, when viewed at a higher magnification, the complicated interface microstructures emerge at some particular regions. Figure 6 shows an example of such complicated ferrite/martensite microstructures. In the BF-TEM image (Fig. 6(a)), there forms an isolated fine grain of ferrite in the vicinity of the original interface that can be again traced by the silicon-oxide particles (Fig. 6(b)). By comparing with the Cr-distribution map of Fig. 6(c), it is evident that the isolated ferrite grain is surrounded by an extended diffusion trace of $\mathrm{Cr}$; this is presumably attributed to a fast diffusion along the prior austenite grain boundaries at $1000^{\circ} \mathrm{C}$. In fact, it was reported that the grain boundary diffusion of $\mathrm{Cr}$ is much faster than balk diffusion in steels. ${ }^{14,15)}$ On the basis of further diffraction contrast analysis, ferrite/martensite distributions within the area of Fig. 6(a) were investigated, and the results are schematically summarized in Fig. 6(d). Suppose that there were pre-existing austenite grain boundaries as drawn in Fig. 6(d), the microstructure evolution at this area is reasonably understood. That is, the extended Cr-enrichment region formed around the pre-existing grain boundaries will transform into martensite even the regions are located within the SPCC layer, and the isolated ferrite island is a consequence of this process.

In order to check whether both the martensite and ferrite crystals adjacent to the original interface were in fact generated from the same parent austenite grain, we performed crystallographic relationship analysis, and compared it with the local composition as summarized in Fig. 7. It is found that, based on the electron diffraction analysis, the crystallographic directions of the ferrite grains (denoted A, B) and the martensite packets (denoted $\mathbf{C}-\mathbf{E}$ ) shown in Fig. 7(a) are almost reasonably interpreted as being generated from the identical parent crystal of austenite; see Fig. 7(d). The orientation relationships between the $\mathbf{A}-\mathbf{E} b c c$ (body-centered cubic) crystals except $\mathbf{B}$ can be fairly well comparable with the possible 24 variants available when assuming both the ferrite/martensite $b c c$ crystals are produced from the parent $f c c$ (face-centered cubic) austenite crystal in accordance with the Kurdjumov-Sachs $f c c / b c c$ orientation relationship. Note that the ferrite grain B, which seems not to posses the Kurdjumov-Sachs orientation relationship with the parent austenite, might be nucleated in another austenite grain adjacent to the parent austenite.

Now we discuss the martensite transformation in terms of local compositions. For the present SPCC/SUS420J2 interface, the martensite has grown extensively to stride over the original interface (Fig. 7(a)). Concerning that all the ferrite/martensite grains in Fig. 7(a) are originated from the single austenite grain annealed at $1000^{\circ} \mathrm{C}$, the continuous composition-gradient across the interface, shown in Figs. 7(b) and 7(c), was basically formed via bulk diffusion within the austenite grain. During quenching from $1000^{\circ} \mathrm{C}$, both the ferrite and martensite start growing, but note that their growth are significantly affected by the local compositions. As seen in Figs. 7(b) and 7(c), the reconstructed ferrite/martensite is indeed located at the slope of the Cr concentration profile; quantitative EDS evaluations revealed that the interface compositions are in the range $1-4 \mathrm{mass} \%$ $\mathrm{Cr}$ for the $0-10-\mathrm{min}$ annealed specimens. Therefore, the ferrite/martensite growth is evidently governed by the local $\mathrm{Cr}$ (and perhaps a certain amount of carbon) contents that have been supplied from the SUS420J2 into the SPCC. With these in mind, the present ferrite/martensite growth during quenching can be presumed as in the following. Firstly, the ferritic transformation occurs in the SPCC side at high temperature $\sim 800^{\circ} \mathrm{C}$, but the ferrite growth would be interrupted when it reaches at the region containing Cr. ${ }^{16)}$ Secondly, with temperature decreasing to the $\mathrm{M}_{\mathrm{s}}$ (martensite start) temperature $\sim 300^{\circ} \mathrm{C}$ of the SUS420J2, the remaining austenite begins to transform into martensite that is able to extend into the SPCC side where a sufficient Cr is supplied.

The overall microstructure evolutions around the present SPCC/SUS420J2 interface are summarized as schematically in Fig. 8. The severe deformed ferrite and martensite 

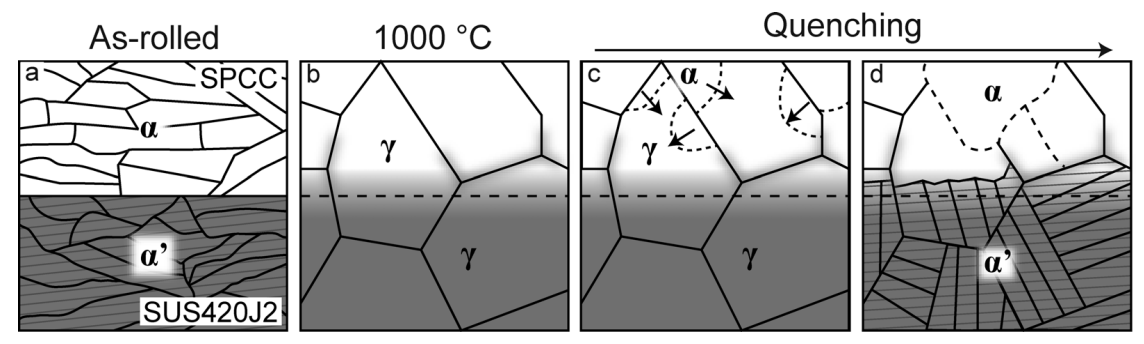

Fig. 8. Schematic illustrations of microstructure evolutions around the SPCC/SUS420J2 interface. Grey to white gradient schematically represents the compositional gradient between the dissimilar steels.

grains (Fig. 8(a)) are immediately transformed into austenite during heating up to and holding at $1000^{\circ} \mathrm{C}$ (Fig. 8(b)). During holding at $1000^{\circ} \mathrm{C}$, the austenite grains continuously grow and stride across the original interfaces, followed by a bulk interdiffusion as well as a fast grain boundary diffusion of the alloying elements including $\mathrm{Cr}$. It is reasonably indicated that the bonding between the dissimilar steels has been mostly obtained at this stage, due to the unification between the layers by the fresh austenite grains. The following water quenching is an indeed necessary process to re-form hard martensitic structure for the SUS420J2 layer. During quenching from $1000^{\circ} \mathrm{C}$, as shown in Fig. 8(c), firstly the SPCC layer is transformed into the ferrite grains probably nucleated from the prior austenite grain boundaries, but their growth is significantly suppressed by the composition-gradient front. During further cooling down, as illustrated in Fig. 8(d), martensite transformation starts when the SUS420J2 layer reaches to the $\mathrm{M}_{\mathrm{s}}$ temperature, growing the martensite lath to cover the remaining austenite regions. It is worth mentioning that the martensitic lath across the reconstructed ferrite/martensite interface might have been nucleated at the SPCC side, because the $\mathrm{M}_{\mathrm{s}}$ temperature increases with decreasing $\mathrm{Cr}$ (and carbon) contents. Interestingly, the ferrite/martensite interfaces in Fig. 7(a) reveal rectilinear shapes, accompanying partially serrated interfaces as shown by dashed lines. Such serration might be due to traces of a primal martensite nucleation at particular habit crystallographic planes of the ferrite crystals, although the final ferrite/martensite interfaces in Fig. 7(a) seem to be not at some simple low-index lattice planes.

Finally, we briefly discuss how the strongly-bonded microstructure can be developed through the annealing/ quenching procedures for the SPCC/SUS420J2 interfaces. As already mentioned, the bonding between the dissimilar steels is primary obtained by the unification of the prior austenite grains (Figs. 8(a) and 8(b)); this is similar to the case for the previous SCM415/SUS304 interface (see Fig. 9 in Ref. 11). It is noteworthy that, even after the ferritic/martensitic transformations that would cause local retained strains, there seem to be no significant cracking or strain accumulation around the interfaces. This is perhaps due to an improved ductile nature of the reconstructed microstructure composed of the fresh austenite and re-transformed ferrite, for which the amount of defects such as dislocations is significantly decreased. For this less-defect ductile austenite/ferrite matrix, the martensite transformation strain can be alleviated without significant strain localization around the ferrite/prior-austenite or ferrite/martensite interfaces. This is also similar to the discussion made for the previous SCM415/SUS304 interface, for which the martensite transformation (SCM415) propagates into the recrystallized ductile austenite (SUS304). In sum, by comparing with the present SPCC/SUS420J2 interface with the previous SCM415/SUS304 interface, they seem to share the fundamental bonding mechanism in the sense that the fresh austenite grains effectively covers and unify the coldrolled original interface, being finished quickly during a short-time annealing.

\section{Summary}

The microstructure evolutions around the cold-rolled SPCC/SUS420J2 interface, which have proceeded during the short time annealing and the following water quenching procedures, have been investigated by STEM-EDS for clarifying how hetero-interface bonding can be achieved through the microstructural reconstructions. We discussed the microstructure evolutions and the corresponding bonding mechanisms by comparison with the previous SCM415/ SUS304 interface. Conclusions of the present work are briefly summarized in the followings.

(1) STEM-EDS analyses around the SPCC/SUS420J2 interfaces have clearly identified the local composition distributions at submicron scales; formation of silicon oxide particles, and Cr composition gradient developed along a few micrometers across the interfaces. Formation of these chemically-diffused interfaces with a moderate composition gradient effectively contributes for the strong bonding at the SPCC/SUS420J2 interfaces.

(2) During annealing at $1000^{\circ} \mathrm{C}$, the cold-rolled SPCC/ SUS420J2 interface microstructure composed of severelydeformed grains is immediately replaced by the fresh austenite grains due to the reverse transformations for both the layers. The fresh austenite grains have grown continuously to stride across the original interfaces, which can be traced by the array of the nanocrystalline silicon-oxide particles. The microstructural reconstruction effectively unifies the original interfaces, and hence it is suggested that the bonding between the SPCC and SUS420J2 layers is primary accomplished at this stage. These features are fairly similar to those observed for the previous SCM415/ SUS304 interface.

(3) During water-quenching from $1000^{\circ} \mathrm{C}$, the $\mathrm{SPCC}$ layer firstly starts transforming into ferrite, but the growth is interrupted when it reaches at the region containing a certain amount of Cr. With temperature decreasing to $M_{s}$ temperature of the SUS420J2, the remaining austenite 
transforms into martensite that is able to extend into the SPCC side where a sufficient $\mathrm{Cr}$ is supplied. Therefore, the $\mathrm{Cr}$ composition-gradient plays a critical role in determining whether ferritic or martensitic transformation becomes dominant; this is comparable to the martensitic transformation previously observed for the SCM415/SUS304 interface, where the martensitic growth was interrupted by $\mathrm{Cr} / \mathrm{Ni}$ composition gradients. It is indicated that the transformation-induced strain localization is not so significant around the present SPCC/SUS420J2 interfaces, and hence the evolutions of the ferrite and martensite microstructures around the interface do not weaken but effectively achieve the strong bonding of the ferrite/martensite interfaces.

\section{Acknowledgement}

This research was supported by LISM (Layer-Integrated Steels and Metals) project funded by Ministry of Education, Culture, Sports, Science and Technology of Japan. The authors gratefully acknowledge helpful discussions with Prof. Koseki, Prof. Suzuki, Dr. Sugiyama, Dr. Koyama, and Dr. Nambu. Special thanks are due to Dr. Michiuchi for taking the SEM images. The authors would also like to thank Dr. Hara for kindly allowing us to use the microscope.

\section{REFERENCES}

1) D. W. Kum, T. Oyama, O. A. Ruano and O. D. Sherby: Metall. Trans. A, 17A (1986), 1517

2) S. Lee, T. Oyama, J. Wadsworth and O. D. Sherby: Mater. Sci. Eng. A, 154 (1992), 133.

3) D. R. Lesuer, C. K. Syn, O. D. Sherby, J. Wadsworth, J. J. Lewandowski and W. H. Hunt, Jr.: Int. Mater. Rev., 41 (1996), 169.

4) O. D. Sherby, J. Wadsworth, R. D. Caligiuri, L. E. Eiselstein, B. C. Snyder and R. T. Whalen: Scr. Metall., 13 (1979), 941.

5) B. C. Snyder, J. Wadsworth and O. D. Sherby: Acta Metall., 32 (1984), 919.

6) C. K. Syn, D. R. Lesuer, J. Wolfenstine and O. D. Sherby: Metall. Trans. A, 24A (1993), 1647.

7) S. Nambu, M. Michiuchi, Y. Ishimoto, K. Asakura, J. Inoue and T. Koseki: Scr. Mater, 60 (2008), 221.

8) J. Inoue, S. Nambu, Y. Ishimoto and T. Koseki: Scr. Mater, 59 (2008), 1055.

9) S. Nambu, M. Michiuchi, J. Inoue and T. Koseki: Compos. Sci. Technol., 69 (2009), 1936.

10) H. D. Manesh: Mater. Sci. Technol., 22 (2006), 634.

11) T. Hayashi, E. Abe, T. Hara and Y. Ikuhara: ISIJ Int., 49 (2009), 1406.

12) M. Michiuchi, S. Nambu, J. Inoue and T. Koseki: Materials Science and Technology Conference and Exhibition MS and T '08, Materials Science and Technology Conference, Westerville, Ohio, USA, (2008), 2539.

13) B. Million, K. Bacilek, J. Kucera, P. Michalicka, A. Rek and K. Stransky: Z. Metall., 86 (1995), 706.

14) J. Čermák: Z. Metall., 81 (1990), 193.

15) J. Čermák, J. Růžičková and A. Pokorná: Scr. Mater., 35 (1996), 411.

16) A. Béché, H. S. Zurob and C. R. Hutchinson: Metall. Mater. Trans. $A, 38$ (2007), 2950 